\title{
Novel biotechnological approaches to produce biological compounds: challenges and opportunities for science communication Lei Pei and Markus Schmidt
}

\begin{abstract}
Novel biotechnological approaches such as Metabolic Engineering (ME) and New Plant Breeding Techniques (NPBTs) are currently being developed to produce biological compounds for food and non-food products. NPBTs span a range of methods for in vivo production in crops, some of which are classified as GMOs while others aren't. Deploying such techniques will not only provide new opportunities for industry, but also challenges with respect to the regulatory environment. Similarly, the process of communicating these new techniques and their products to stakeholders and consumers will not be without its own challenges. We argue that scientists should engage more with non-scientists, either directly or through collaborators. These engagements should not only be about the science, we suggest, but also explicitly deal with real world ramifications, such as economic, environmental and social issues.
\end{abstract}

\author{
Address \\ Biofaction KG, Vienna, Austria \\ Corresponding author: Schmidt, Markus (schmidt@biofaction.com)
}

Current Opinion in Biotechnology 2019, 56:43-47

This review comes from a themed issue on Food biotechnology

Edited by Rute Neves and Herwig Bachmann

https://doi.org/10.1016/j.copbio.2018.08.012

0958-1669/@ 2018 Published by Elsevier Ltd.

\section{Introduction}

Biological compounds are molecules originally produced by living organisms, ranging from microbes, to plants and animals. They can be used as food additives (such as colorants and flavors), nutraceuticals (such as dietary supplements and functional foods), as well as pharmaceuticals (such as anti-inflammatory and anti-microbial compounds). Because of the combined effects of population growth, aging, climate change, natural disasters, and so on. The current agricultural capacity can hardly meet the growing demand for food and non-food products produced in traditional cultivation, and certainly not in a sustainable manner [1].
The first generation of genetic engineering (GE1.0) techniques (mainly by the use of recombinant DNA technology) have already been applied to engineer biosynthetic pathways in microbes and plants to produce for example Vitamin C [2], vanillin [3], or monoclonal antibodies-specific to Ebola [ $4^{\bullet \bullet}$ ]. In terms of public perception it was shown that using GE1.0 to produce biological products for pharmaceuticals did not lead to very critical views or resistance [5-8]. However, when GE1.0 technology was used to produce food and feed or food additives, especially in Europe, these products were always controversial in public debate. Concerns raised impinged not only on technical issues (such as safety to humans, animals and the environment), but also covered ethics, patents, politics, transparency, and so on [9].

So while (bio)technological improvements in the production of biological compounds for food and non-food purposes are necessitated by global trends, there are many countries around the world where the public is rather critical towards biotechnological innovations, especially when it comes to food. How can this puzzle be solved in a democratic way?

One possible solution is to leave the partly stigmatized first generation of genetic engineering techniques and products behind and concentrate on the next generation that is GE2.0. This second generation represents ongoing improvements in the field of synthetic biology $\left[10^{\circ}\right]$. Among them, metabolic engineering (ME) on microbial production systems and new plant breeding techniques (NPBTs) to develop new plant varieties are commonly applied to produce bioactive compounds for food and non-food purposes. ME (re)designs-specific biosynthetic pathways in new host cells in order to improve the production by broadening the substrate range and increasing yield and productivity. While ME has been available for several years [11], current synergies from systems and synthetic biology, as well as bioinformatics, have recently increased its potential $[12,13]$. For example, ME has been applied to enable Escherichia coli to produce polyphenol compounds that are normally only produced in plants such as berries and that can be used as food colorants or as candidates for anti-inflammatory, antioxidant, or antibiotic drugs $\left[14^{\bullet \bullet}\right]$.

In most cases, NPBTs differ from the processes that generate genetically modified organisms (GMOs). The differences is significant, in fact, some of the plants 
produced with NPBT are not legally classified as GMOs at all. At least eight NPBTs have been evaluated by the European Food Safety Authority (EFSA) [15,16]: Znfinger nuclease (ZFN), oligonucleotide directed mutagenesis, cisgenesis and intragenesis, RNA-dependent DNA methylation, grafting, reverse breeding, agro-infiltration, and synthetic genomics. In addition, the rapid development of the gene (genome) editing tools such as Transcription Activator-Like Effector Nuclease (TALEN) and Clustered Regularly Interspaced Short Palindromic Repeats (CRISPR)-Cas9, contributed significantly to the inventory list of NPBTs $[17,18]$. A handful of plants have been modified by NPBTs and made it to the market, such as CRISPR edited anti-browning mushrooms and soybeans with drought and salt tolerance [ $\left.{ }^{\circ} 9^{\circ}\right]$. Furthermore, NPBTs can be used to convert plants into cell factories to produce bioactive compounds, for example, the newly granted European $\mathrm{H} 2020$ projects NEWCOTIANA (https://newcotiana.org) and CHIC (http:// chicproject.eu) use NPBTs to convert tobacco and chicory to produce bioactive compounds for pharmaceuticals, cosmetics, and dietary fibre.

Apart from the technical feasibility and economic potential of these bioprocesses, the cultural aspects and other societal issues have to be taken into account. The stakeholders involved in GE2.0 are more diverse than in GE1.0. On top of industry, academia, and regulatory authorities, other stakeholders play decisive roles: consumer groups, small growers or indigenous resource suppliers, environmental/health advocacy groups, and so on.

With more stakeholders involved, (science) communication between them and with the public becomes more important. Based on past experiences with public perception of emerging technologies, it is apparent that comprehensive science communication is important for the responsible development and deployment of these techniques, as described in the responsible research and innovation (RRI) framework $\left[10^{\bullet}, 20^{\bullet \bullet}, 21\right]$. GE2.0 faces challenges as well as opportunities for science communication, while balancing the competing interests of different stakeholders.

\section{Challenges for communicating ME and NPBT}

Because of the sometimes counterintuitive regulations of biotech products, which are sometimes regulated by the product itself, sometimes by the process used to make it, or a combination of both [22], communication about these products/processes is not straightforward. Up to date, for biological compounds produced by $\mathrm{ME}$, the regulation is relatively clear: they are regulated based on product category [23]. Take for example vanillin produced by $\mathrm{ME}$ yeast when using sugar as starting material. If the vanillin is used as food additive, the labelling of the compound is 'natural aroma' although it doesn't stem from the real vanilla plant, because it was not chemically synthesized $[3,24,25]$. For biological compounds produced by NPBTs, there are only a few governmental decisions regarding whether a product produced by NPBTs should or should not be declared a GMO (for more detail, see Table 1) $\left[19^{\bullet}, 26,27^{\bullet}, 28\right]$. The de-regulation on editing plants with CRISPR announced by the US Department of Agriculture in March 28th, 2018 have paved a way to market the products produced by NPBTs, or more specific, CRISPR edited plants for food and nonfood applications (e.g. mushroom, maize and soybean) $\left[19^{\circ}\right]$. The European Court of Justice (ECJ) went the other direction and classified CRISPR edited plants as GMOs [29], a decision that puzzled many plant scientists in Europe and led many to question the reasoning of this decision. Such ruling might hinder the NBPTs in Europe from research to investigation, while at the same time the proper enforcement of such ruling is in question [30]. There are two examples summing up very well the communication challenges in ME and NPBT: while vanillin produced by engineered yeast for food products is supposed to be 'natural', a plant with a single base modification in the genome that could have occurred naturally, is classified as a GMO.

\section{Opportunities for science communication}

The biggest communication opportunities with respect to ME and NPBTs arise when the technology can be deployed for the betterment of humankind and the planet, as defined by the United Nations sustainable development goals (UN-SDGs) [31]. While the first generation of GM-crops, for example, where hardly designed with sustainability goals in mind, a more responsible approach to innovation can hopefully steer ME and NPBTs in this, right, direction.

Examples that show this include: the successful production of semi-synthetic artemisinin (acid) serving as an alternative stable supply for anti-malaria drugs [32]; or current attempts to produce polyphenol compounds, known for their positive effects on health and longevity and normally found in berries, in cell factories, thus saving arable land [33]; or NPBTs that repurpose non-food plants like tobacco to produce cosmetics and pharmaceuticals. Communicating this potential may provide scientists a window of opportunity to restart a conversation with the public and all relevant stakeholders [31].

\section{Engaging in a two-way communication}

The real world success of novel techniques depends very much on the particular cultural, social and economic context and can be heavily influenced by public opinion $\left[20^{\circ \bullet}\right]$. While scientists (and European regulators) tend to highlight mostly the techniques themselves, consumers are more interested in the final product $\left[34^{\circ}\right]$. While the biological compounds for food and non-food applications produced via biosynthesis processes are available, it is 
Table 1

\begin{tabular}{|c|c|c|c|c|c|c|c|c|c|c|c|}
\hline & $\begin{array}{l}\text { SDN1 } \\
\text { ZFN1 }\end{array}$ & \begin{tabular}{|l} 
SDN2 \\
ZFN2
\end{tabular} & $\begin{array}{l}\text { SDN3 } \\
\text { ZFN3 }\end{array}$ & $\begin{array}{l}\text { CRISPR- } \\
\text { Cas9 }\end{array}$ & ODM & CisGen & RdDM & RevB & Grafting & AgrolF & Ref \\
\hline Argentina & $\begin{array}{l}\begin{array}{l}\text { Case by } \\
\text { case }\end{array} \\
\end{array}$ & $\begin{array}{l}\text { Case by } \\
\text { case }\end{array}$ & & & $\begin{array}{l}\text { Case by } \\
\text { case }\end{array}$ & & & \begin{tabular}{|l|}
$\begin{array}{l}\text { Case by } \\
\text { case }\end{array}$ \\
\end{tabular} & & & [27] \\
\hline Australia & & $\begin{array}{l}\text { Case by } \\
\text { case }\end{array}$ & $\begin{array}{l}\text { Case by } \\
\text { case }\end{array}$ & & $\begin{array}{l}\text { Case by } \\
\text { case }\end{array}$ & $\begin{array}{l}\text { Case by } \\
\text { case }\end{array}$ & & & & $\begin{array}{l}\text { Case by } \\
\text { case }\end{array}$ & {$[26,27]$} \\
\hline Canada * & & & & & & & & & & & {$[26,27,36]$} \\
\hline Japan & & & & & & & & & $\begin{array}{l}\text { Case by } \\
\text { case }\end{array}$ & & {$[26]$} \\
\hline New Zealand & $\begin{array}{l}\begin{array}{l}\text { Case by } \\
\text { case }\end{array} \\
\end{array}$ & & & & & & & & & & [26] \\
\hline Switzerland & & & & & & & & & & & [26] \\
\hline US & $\begin{array}{l}\begin{array}{l}\text { Case by } \\
\text { case }\end{array} \\
\end{array}$ & $\begin{array}{l}\begin{array}{l}\text { Case by } \\
\text { case }\end{array} \\
\end{array}$ & $\begin{array}{l}\text { Case by } \\
\text { case }\end{array}$ & & & $\begin{array}{l}\text { Case by } \\
\text { case }\end{array}$ & & & & & {$[27,37]$} \\
\hline$E C J^{\star \star}$ & GM & GM & GM & GM & GM & & & & & & [29] \\
\hline EU-EFSA ${ }^{* \star *}$ & \begin{tabular}{|l|} 
As \\
mutagen \\
esis
\end{tabular} & \begin{tabular}{|l} 
As \\
mutagene \\
sis
\end{tabular} & $\begin{array}{l}\text { As self- } \\
\text { cloning }\end{array}$ & & $\begin{array}{l}\text { As } \\
\text { mutagene } \\
\text { sis }\end{array}$ & $\begin{array}{l}\text { As } \\
\text { traditional } \\
\text { breeding }\end{array}$ & $\begin{array}{l}\text { Intermedi } \\
\text { ate as } \\
\text { GM }\end{array}$ & \begin{tabular}{|l} 
Non-GM \\
homozyg \\
ous
\end{tabular} & $\begin{array}{l}\text { Case by } \\
\text { case }\end{array}$ & $\begin{array}{l}\text { GMM } \\
\text { present }\end{array}$ & {$[15,38,39]$} \\
\hline Austria & & & & & & & & & $\begin{array}{l}\text { Case by } \\
\text { case }\end{array}$ & & [40] \\
\hline Germany & & & & & & $\begin{array}{l}\text { GM or } \\
\text { non-GM }\end{array}$ & $\begin{array}{l}\text { GM or } \\
\text { non-GM }\end{array}$ & $\begin{array}{l}\text { GM or } \\
\text { non-GM }\end{array}$ & $\begin{array}{l}\text { GM or } \\
\text { non-GM }\end{array}$ & $\begin{array}{l}\text { GM or } \\
\text { non-GM }\end{array}$ & [41] [42] \\
\hline Netherlands & & & & & & & & & $\begin{array}{l}\text { Non-GM } \\
\text { part }\end{array}$ & & [43] \\
\hline Sweden & & & & & & & & & & & [44] \\
\hline
\end{tabular}

Adapted from Schuttelaar \& Partners [26]

*Product-based approach, GMO regulation triggered by novel traits but not by breeding techniques used.

${ }^{*}$ European Court of Justice (ECJ) decided that GMO rules covered plants developed via mutagenesis made by NPBTs, according to the ruling published on July 25, 2018.

${ }^{* * \star}$ European Food Safety Authority (EFSA) is the agency of the European Union (EU) that provides independent scientific advice on issues related to food safety.

SDN site directed nuclease, SDN1 for site mutation, SDN2 for delection, and SDN3 for insertion; ZFN zinc finger nuclease; CRISPR-Cas9 clustered regularly interspaced short palindromic repeats-Cas9; ODM Oligonucleotide-directed mutagenesis; CisGen cisgenesis and/or intragenesis; RdDM RNA-dependent DNA methylation; RevB reverse breeding; Grafting covering non-GM scion with GM root and GM scion with non-GM root, with or without horizontal genome transfer events; AgrolF agroinflitration; GM for genetically modified organism; GMM for genetically modified microorganism. Cells filled in green are most likely exempted from GMO regulation; cells filled in yellow will be regulated as GMO (or likely); for empty cells in blank there is no information available or it remains inconclusive.

time to deploy a comprehensive communication strategy, covering not only scientific topics, but also non-technical topics to help the public get a $360^{\circ}$ view on the products (and processes).

The research community should use this opportunity to engage in a two-way communication, explaining the new techniques, but also listening to the hopes and concerns of the public. In order to participate in such a two-way communication, scientists need to appreciate the societal ramifications of their work. The science alone will hardly convince the public and consumers. Economic, cultural and societal issues have to be taken into account, and be afforded at least the same importance in the communication process [9]. This way, the scientific community could take up a more responsible role contributing to a flourishing future society, and along the way scientists and the rest of society can learn from each other.

One way to do this is by establishing collaborations with traditional and new media, such as bloggers, podcasts, youtube channels, and instagrammers who may but don't have to specialize in science issues. Conventional science communication channels tend to 'preach to the converted', in other words, target people who already have a very positive attitude towards science (think of science fairs, science nights, science cafes etc.). Creative science communication goes beyond that, venturing out of the science communication comfort zone into unchartered territory: the field where the innovations are actually applied. For example, when it comes to food, collaborating with famous chefs, gastronomy media outlets or food festivals will have a much higher impact when it comes to introducing novel compounds or more sustainable production methods. Demonstrating the benefit for the consumer or end user is paramount, either through new experiences, better quality, more sustainability or any other parameter that matters to consumers. In this short article, we can certainly not provide an operational manual on how to engage with these unconventional collaborators. Each field has its own memes, influencers, tradition and practices, and so on, so each field needs a carefully designed approach. We only underline that collaborations with players at the 'innovation frontline' can be highly effective.

Some applications are specific, such as vanillin for food or tobacco for health, while other forms of research target more abstract problems. In the more abstract cases, collaboration between scientists and artists might make sense to translate scientific concepts into the world of art, thus reaching a whole new audience [35]. 
But even without collaborators, today's researchers have social media tools at hand that allow then (at least theoretically) to communicate with the whole world directly. While researchers have been trained to produce valid scientific results, most curriculums lack a sound training in communication to non-peer groups. Although some researchers are natural born communicators, most scientists would benefit a lot by training courses. This is why, for example, the Innovative Training Networks (ITN) for early stage researchers supported by the EC, focuses also on these skills, providing training workshops considering social media as well as traditional channels (see e.g. the ITN SynCrop: http://www.syncrop.org/). To give an example: in recent years, scientific journals started to welcome additional video abstracts to briefly explain the publications (see e.g. https://www.youtube.com/ watch? $v=x r X y R J V 96 m k)$, but few scientists know how to make such videos. In training workshops titled 'Audiovisual Storytelling', scientists learn how to create a visual storyboard that is the basis for this kind of video production. These short videos are perfect for social media channels as they convey a visually attractive, well crafted message in a short time period. Investing more time in specific training to prepare scientists for two-way communication with non-peer groups, using traditional and social media channels, will increase trust in science and strengthen responsible innovation. In the past, some PIs have been reluctant to allow young scientists time away from the bench, but on the mid and long term, these skills not only pay off for the individual career for the young scientists (of which their former supervisor should be proud of), but also directly improve the interface between science and society.

\section{Conclusion}

The foreseeable increase in world population, its accompanying demands for resources, and the need to reach the global sustainability goals, seem to be challenges that are hard if not impossible to solve. One way of dealing with these challenges is found in the development and use of novel biotechnological methods such as ME and NPBTs to increase not only the efficiency of the food and nonfood production systems, but also the capacity to produce new types of compounds. While in the past, genetic engineering and its technocratic implementation was met with public resistance, the next generation of biotechnological approaches has to take the economic, cultural and societal issues more serious. Communication between researchers on the one hand, and stakeholders and the public on the other hand will play a decisive role in establishing a two-way communication with the aim to re-establish trust and introduce new sustainable products in a responsible manner. On top of conventional science communication we advocate collaboration with application-specific multipliers and artists to enlarge the audience, to customize the narrative and to become more effective communicators.

\section{Conflict of interest statement}

Nothing declared.

\section{Acknowledgements}

The authors would like to thank Sandra Youssef for English proofreading and Ege Koekel for the figure. This work has been supported by European Commission Horizon 2020 Project NEWCOTIANA (Developing Multipurpose Nicotiana Crops for Molecular Farming using New Plant Breeding Techniques) [EC 760331].

\section{References and recommended reading}

Papers of particular interest, published within the period of review, have been highlighted as:

- of special interest

-. of outstanding interest

1. FAO: The Future of Food and Agriculture - Trends and Challenges. FAO; 2017.

2. Yang $\mathrm{W}, \mathrm{Xu} \mathrm{H}$ : Industrial fermentation of vitamin C. In Industrial Biotechnology of Vitamins, Biopigments, and Antioxidants. Edited by Vandamme EJ, Revuelta JL. Wiley-VCH Verlag; 2016:161-192.

3. Gallage NJ, Moller BL: Vanillin-bioconversion and bioengineering of the most popular plant flavor and its de novo biosynthesis in the vanilla orchid. Mol Plant 2015, 8:40-57.

4. Zeitlin L, Pettitt J, Scully C, Bohorova N, Kim D, Pauly M, Hiatt A,

- Ngo L, Steinkellner H, Whaley KJ et al:: Enhanced potency of a fucose-free monoclonal antibody being developed as an Ebola virus immunoprotectant. Proc Natl Acad Sci U S A 2011, 108:20690-20694.

The article showed how agroinfiltration (one of the NBPTs) has been applied in tobacco plant to produce biological compounds for pharmaceutical use.

5. Gaskell G, Allansdottir A, Allum N, Castro P, Esmer Y, Fischler C, Jackson J, Kronberger N, Hampel J, Mejlgaard N et al.: The 2010 Eurobarometer on the life sciences. Nat Biotechnol 2011, 29:113-114

6. TNS Opinion \& Social: Eurobarometer 73.1: Biotechnology. 2010 Available at: http://ec.europa.eu/public_opinion/archives/ebs/ ebs 341 en.pdf.

7. Hart Research Associates: Awareness \& Impressions of Synthetic Biology. 2013 . Available at: http://www.synbioproject.org/site/ assets/files/1289/synbiosurvey2013.pdf.

8. Hart Research Associates: Awareness \& Impressions of Synthetic Biology. 2010 . Available at: https://www.bio.org/sites/default/ files/hart2010report_final_0.pdf.

9. Blancke S, Grunewald W, De Jaeger G: De-problematizing 'GMOs': suggestions for communicating about genetic engineering. Trends Biotechnol 2017, 35:185-186.

10. Pei L, Schmidt M: Synthetic biology: from genetic engineering

- $\quad 2.0$ to responsible research and innovation. In Synthetic Biology: Parts, Devices and Applications. Edited by Smolke C, Lee SY, Nielsen J, Stephanopoulos G. Wiley; 2018:373-402.

This book chapter provided a review on how RRI to be incoporated into research and innovation of emerging science.

11. Stephanopoulos G: Synthetic biology and metabolic engineering. ACS Synth Biol 2012, 1:514-525.

12. Nielsen J, Keasling JD: Synergies between synthetic biology and metabolic engineering. Nat Biotechnol 2011, 29:693-695.

13. King JR, Edgar S, Qiao K, Stephanopoulos G: Accessing nature's diversity through metabolic engineering and synthetic biology. F1000Res 2016:5.

14. Dudnik A, Almeida AF, Andrade R, Avila B, Bañados $P$, Barbay $D$

- Bassard J-E, Benkoulouche M, Bott M, Braga A et al.: BacHBerry: BACterial hosts for production of bioactive phenolics from bERRY fruits. Phytochem Rev 2017, 17:291-326.

Authors highlighted how ME has been applied to engineer microbial cell factoryE. coli strains to produce plant polyphenol compounds. 
15. EFSA: New Techniques Working Group: Final Report. 2011. Available at: $h$ ttp://wWw.seemneliit.ee/wp-content/uploads/2011/ 11/esa_12.0029.pdt.

16. Lusser M, Parisi C, Plan D, Rodríguez-Cerezo E: New Plant Breeding Techniques State-of-the-Art and Prospects for Commercial Development. Publications Office of the European Union; 2011.

17. Baltes NJ, Voytas DF: Enabling plant synthetic biology through genome engineering. Trends Biotechnol 2015, 33:120-131.

18. Bortesi L, Fischer R: The CRISPR/Cas9 system for plant genome editing and beyond. Biotechnol Adv 2015, 33:41-52.

19. Waltz E: With a free pass, CRISPR-edited plants reach market - in record time. Nat Biotechnol 2018, 36:6-7.

This news provided an update on the latest products in the market developed based on NPBTs.

20. Malyska A, Bolla R, Twardowski T: The role of public opinion in

-• shaping trajectories of agricultural biotechnology. Trends Biotechnol 2016, 34:530-534.

This opinion article pointed out a paradigm shift of science communication for emerging technologies, particularly those of NPBTs.

21. Araki M, Ishii T: Towards social acceptance of plant breeding by genome editing. Trends Plant Sci 2015, 20:145-149.

22. Pollock CJ: How should risk-based regulation reflect current public opinion? Trends Biotechnol 2016, 34:604-605.

23. NAS: Preparing for Future Products of Biotechnology. 2017. Available at: http://www.nap.edu/24605.

24. Friends for the Earth: Synthetic Biology Vanillin: Not Natural, Not Sustainable, Not Likely to be Labeled, and Coming to an Ice-cream Cone Near You. 2013 . Available at: http://www.synbiowatch.org/ wp-content/uploads/2013/09/synbio_vanillin_fact_sheet.pdf.

25. Sabisch M, Smith D: The Complex Regulatory Landscape for Natural Flavor Ingredients. 2012 . Available at: https://www. sigmaaldrich.com/technical-documents/articles/white-papers/ flavors-and-fragrances/natural-flavor-ingredients-regulations. html.

26. Schuttelaar \& Partners: The Regulatory Status of New Breeding Techniques in Countries Outside the European Union. Schuttelaar \& Partners; 2015.

27. Whelan Al, Lema MA: Regulatory framework for gene editing

- $\quad$ and other new breeding techniques (NBTs) in Argentina. GM Crops Food 2015, 6:253-265.

This review article summarized not only regulation framework for NPBTs in Argentina but also reviewed regulatory approaches from other countries (US, Canada, Australia, New Zealand, EU and OECD).

28. POST: In New Plant Breeding Techniques. Edited by Parliament Ho. Houses of Parliament; 2017.

29. Banks M: ECJ rules that' new breeding techniques' are GMOs. Parliament Magazine. Dods Parliamentary Communications Ltd.; 2018.

30. Associated Press: EU Top Court Rules New Breeding Techniques Count as GMOs. The New York Times; 2018.
31. de Lorenzo V, Prather KL, Chen GQ, O’Day E, von Kameke C, Oyarzun DA, Hosta-Rigau L, Alsafar H, Cao C, Ji W et al.: The power of synthetic biology for bioproduction, remediation and pollution control: the UN's Sustainable Development Goals will inevitably require the application of molecular biology and biotechnology on a global scale. EMBO Rep 2018, 19:e45658.

32. Paddon CJ, Keasling JD: Semi-synthetic artemisinin: a model for the use of synthetic biology in pharmaceutical development. Nat Rev Microbiol 2014, 12:355-367.

33. Pei L, Schmidt M: Sustainable assessment on using bacteria platform to produce high-added-value products from berries through metabolic engineering. In Systems Biology Application in Synthetic Biology. Edited by Springer SS. 2016:71-78.

34. Gaskell G, Bard I, Allansdottir A, da Cunha RV, Eduard P,

- Hampel J, Hildt E, Hofmaier C, Kronberger N, Laursen S et al:: Public views on gene editing and its uses. Nat Biotechnol 2017 , 35:1021-1023

This correspondence article reported the online surveys on public opinions on gene editing. Although it was more on clinical applications of the gene editing, it showed that societal content was important to guide innovative technological applications.

35. Schmidt M (Ed): The art of Antibiotics. Biofaction KG; 2018.

36. Smyth SJ: Canadian regulatory perspectives on genome engineered crops. GM Crops Food 2017, 8:35-43.

37. Wolt JD, Wang K, Yang B: The regulatory status of genomeedited crops. Plant Biotechnol J 2016, 14:510-518.

38. EFSA: Scientific opinion addressing the safety assessment of plants developed through cisgenesis and intragenesis. EFSA J 2012, 10:2561.

39. EFSA: Scientific opinion addressing the safety assessment of plants developed using zinc finger nuclease 3 and other sitedirected nucleases with similar function. EFSA J 2012, 10:2943.

40. AGES: New Plant Breeding Techniques. RNA-Dependent Methylation, Reverse Breeding, Grafting. Bundesministerium für Gesundheit; 2013.

41. ZKBS: In Position Statement of the ZKBS on New Plant Breeding Techniques. Edited by Lebensmittelsicherhei BfVu. 2012.

42. BVL: Opinion on the Legal Classification of New Plant Breeding Techniques, in Particular ODM and CRISPR-Cas9. 2017. Available at: https://www.bvl.bund.de/SharedDocs/Downloads/ 06_Gentechnik/Opinion_on_the_legal_classification_of_New_ Plant_Breeding Techniques.pdf? blo $\bar{b}=$ publicationFile $\& v=2$.

43. Schaart J, Visser R: Novel Plant Breeding Techniques: Consequences of New Genetic Modification-Based Plant Breeding Techniques in Comparison to Conventional Plant Breeding. PRI Biodiversity and Breeding Laboratory of Plant Breedin; 2009.

44. Jansson S, Sundström J: "Green Light in the Tunnel"! Swedish Board of Agriculture: A CRISPR-Cas9-mutant but not a GMO. 2016 . Available at: https://www.upsc.se/about-upsc/news/ 4815-green-light-in-the-tunnel-swedish-board-of-agriculturea-crispr-cas9-mutant-but-not-a-gmo.html. 